DOI: $10.17976 / \mathrm{jpps} / 2020.01 .07$

\title{
КАК ИЗМЕРЯТЬ МЯГКУЮ СИЛУ В МЕЖДУНАРОДНЫХ ОТНОШЕНИЯХ
}

\section{Дж. Галларотти}

ГАЛЛАРОТТИ Джулио, профессор факультета управлений, Уэслианский университет, Мидлтаун (Коннектикут), США, email: ggallarotti@wesleyan.edu

Галларотти Дж. Как измерять мягкую силу в международных отношениях. - Полис. Политические исследования. 2020. № 1. С. 89-103. https://doi.org/10.17976/jpps/2020.01.07

Автор благодарит за комментарии коллег Алину Владимирову, Сергея Чугрова и участников секции “Энергетический аудит в международных отношениях" на панельном заседании Конгресса Международной ассоциации политической науки, Брисбен, Австралия, 21-24 июля 2018 г. Автор также выражает благодарность Уэслианскому университету за финансовую поддержку при организации поездки на Конгресс.

Статья поступила в редакцию: 01.01.2019. Принята к публикации: 11.11.2019

Аннотация. В статье формулируются предложения автора по вопросам более эффективной оценки мягкой силы в международных отношениях, а также дифференциации ее количественных показателей по категориям, в наибольшей степени соответствующим стратегии количественного анализа. В центре внимания находится наиболее популярный и широко применяемый показатель - индекс мягкой силы “The Soft Power 30 Index". По мнению автора, распространенные методы количественного анализа мягкой силы на основе наиболее популярных наборов данных не лишены недостатков. Проанализировав эти методы, автор предлагает собственный набор индикаторов, призванный сделать анализ мягкой силы более эффективным.

Ключевые слова: мягкая сила, жесткая сила, количественные методы исследования, индексы, операционализация, международные отношения.

\section{ОСНОВНЫЕ СУЩЕСТВУЮЩИЕ СРЕДСТВА ИЗМЕРЕНИЯ МЯГКОЙ СИЛЫ}

С ростом внимания к мягкой силе позитивисты и приверженцы количественных методов исследований искали способы все более точной оценки ее природы. Как следствие, за последнее десятилетие был разработан целый ряд новых индексов. До появления сводных индексов мягкую силу главным образом оценивали исходя из опросов общественного мнения, таких как, например, Pew Global Attitude Survey [McClory 2012: 6]. Первый сводный индекс мягкой силы (Institute for Government - Monocle Soft Power Index) был разработан в 2010 г., и с тех пор публикуется ежегодно для нескольких стран [ibid: 7-8]. Индекс складывается из пяти категорий индикаторов: управление, культура, дипломатия, образование и бизнес/инновации, а также включает ряд субъективных категорий, предлагаемых экспертами. Каждый из этих индексов подразделяется на соответствующие подындексы.

1) Дипломатия:

- зарубежная помощь (пропорционально валовому национальному доходу),

- зарубежная помощь (всего),

- безвизовый режим,

- количество культурных миссий,

- количество посольств в стране, 
- количество посольств и консульств за рубежом,

- общее число постоянных дипломатических миссий в многосторонних организациях,

-общее количество международных / многосторонних организаций, в которые входит страна,

- количество подписанных экологических договоров,

- количество просителей убежища.

2) Управление:

- показатель индекса человеческого развития $\mathrm{OOH}$,

- эффективность правительства,

- личные свободы,

- демократические институты,

- наличие исследовательских центров,

- теневая экономика,

- насилие в обществе,

- подотчетность правительства,

- наличие смертной казни,

- доверие правительству,

- неравенство в доходах (индекс Джини).

3) Культура:

- туризм,

- расходы туристов,

90 - аудитория государственных СМИ,

- присутствие иностранных корреспондентов,

- влиятельность языка,

- участие в олимпийских играх,

- размер музыкального рынка,

- глобальные показатели продаж аудио- и видеозаписей,

- посещаемость художественных галерей,

- число расположенных в стране объектов всемирного наследия ЮНЕСКО,

- статус в международной федерации футбола (ФИФА),

- успешность кинофестивалей.

4) Образование:

- качество начального и среднего образования (PISA),

- число высокорейтинговых университетов,

- иностранные студенты,

- академическая публикационная активность.

5) Бизнес и инновации:

- международные патенты,

- конкурентоспособность бизнеса,

- уровень коррупции,

- индекс инноваций,

- иностранные инвестиции,

- доступность интернета. 
6) Субъективные категории (по данным экспертных опросов):

- значимость национальной культуры,

- качество национальной еды и напитков,

- субъективная мера относительной привлекательности кумиров массовой культуры,

- качество национальной авиакомпании/аэропорта,

- глобальное лидерство,

- дизайн/архитектура,

- оценка привлекательности национальных коммерческих брендов.

Отчет компании Elenco Global Presence (2015) содержит количественную оценку влияния стран Европейского союза, а также самого ЕС на ряд категорий власти: экономическое присутствие, военное присутствие и "мягкое присутствие” (аналог мягкой силы). Сводный индекс рассчитывается по следующим категориям индикаторов (см. табл. 1).

Таблица 1 (Table 1)

\section{Компоненты индекса "мягкого присутствия" Elenco}

Soft Presence Index Components of the Elenco

\begin{tabular}{|l|l|}
\hline Миграция & Оценочная численность иммигрантов извне ЕС \\
\hline Туризм & Число прибывающих туристов извне ЕС \\
\hline Спорт & $\begin{array}{l}\text { Взвешенная сумма очков в мировом рейтинге ФИФА и медалей, } \\
\text { завоеванных на летних Олимпйскх играх по каждой стране - } \\
\text { члене ЕС }\end{array}$ \\
\hline Культура & $\begin{array}{l}\text { Экспорт аудиовизуальных услуг за пределы ЕС } \\
\text { (кинематографическая продукция, радио- и телевизионные } \\
\text { программы, музыкальные записи) }\end{array}$ \\
\hline Технология & $\begin{array}{l}\text { Максимальная пропускная способность интернета (Мбит/с) } \\
\text { в странах-членах ЕС }\end{array}$ \\
\hline Наука & $\begin{array}{l}\text { Зарубежно-ориентированные патенты для всех стран-членов } \\
\text { ЕС: количество взаимосвязанных патентных заявок, поданных } \\
\text { в одной или нескольких зарубежных странах для защиты одного } \\
\text { изобретения }\end{array}$ \\
\hline Образование & $\begin{array}{l}\text { Количество статей, заметок и обзоров авторов из стран-членов ЕС, } \\
\text { опубликованных в области социогуманитарных и естественных } \\
\text { наук }\end{array}$ \\
\hline $\begin{array}{l}\text { Сисло иностранных студентов из стран, не входящих в ЕС, } \\
\text { в высших учебных заведениях ЕС }\end{array}$ \\
\hline
\end{tabular}

Также хорошо известен индекс мягкой силы Ирэн Ву (Wu Rubric for Soft Power), который дает сравнительную оценку мягкой силе России и Китая на базе четырех интегральных показателей. Описание индекса гласит:

"Мягкая сила - это способность страны влиять на международное сообщество, привлекая симпатии других, а не с помощью экономических рычагов или военной силы".

Под мягкой силой обычно понимают проекцию власти (например, сколько фильмов снято в Индии или сколько программ общественной дипломатии было организовано).

\footnotetext{
${ }^{1}$ Wu I.S. Wu Rubric for Soft Power. 2019. URL: https://www.arcgis.com/apps/MapSeries/index.html?appid= c2085de7ac0d47cfade2aa26ec665dcc (accessed 03.12.2019).
} 
Что если посмотреть с другой стороны и подумать о том, каков образ страны в глазах иностранцев? Какие действия предпринимают люди, если их привлекает чужая страна? Индекс мягкой силы И. Ву позволяет оценить эти аспекты.

1) Эмиграция: принимая решение об эмиграции, жители страны назначения переходят из категории “они” в категорию “мы”.

2) Обучение за рубежом: выезжая за границу, студенты проявляют серьезный интерес к стране назначения, по аналогии с "отслеживанием" ее в соцсетях.

3) Зарубежная поездка: посещение страны означает выражение к ней интереса и симпатии, по аналогии с “лайком” в соцсетях.

4) Кинематограф: просмотр иностранного фильма - это кратковременное погружение в другую культуру.

И. Ву операционализирует эти переменные следующим образом:

1) динамика числа иммигрантов из различных стран;

2) количество иностранных студентов;

3) количество туристов;

4) аудитория китайских фильмов, российских фильмов и фильмов совместного производства.

Наиболее известен индекс The Soft Power $30^{2}$, на базе которого составляется рейтинг 25 ведущих стран мира по уровню их мягкой силы. Индекс разработан совместно с Facebook, учитывает более 75 индикаторов и результаты опросов массового мнения более 11 тыс. чел. (см. табл. 2).

Таблица 2(Table 2)

Рейтинг глобальных ресурсов мягкой силы The Overall Ranking of the Global Resources of Soft Power

\begin{tabular}{|l|l|}
\hline Цифровая сфера & $\begin{array}{l}\text { Цифровая инфраструктура страны и ее возможности } \\
\text { в области цифровой дипломатии }\end{array}$ \\
\hline Культура & $\begin{array}{l}\text { Глобальный охват и привлекательность культурных } \\
\text { достижений нации - как поп-культуры, так и высокой культуры }\end{array}$ \\
\hline Предпринимательство & $\begin{array}{l}\text { Привлекательность экономической модели страны, } \\
\text { “ружелюбная” бизнес-среда и способность к инновациям }\end{array}$ \\
\hline Образование & $\begin{array}{l}\text { Качество человеческого капитала в стране, вложения } \\
\text { в стипендиальный фонд и привлекательность для } \\
\text { иностранных студентов }\end{array}$ \\
\hline Вовлеченность & $\begin{array}{l}\text { Влиятельность дипломатической сети страны и ее вклад } \\
\text { в глобальное взаимодействие и развитие }\end{array}$ \\
\hline управление & $\begin{array}{l}\text { Приверженность свободе, правам человека и демократии, } \\
\text { а также качеству политических институтов }\end{array}$ \\
\hline
\end{tabular}

Эти индикаторы операционализированы следующим образом.

1) Культура:

- общее количество прибывающих туристов,

- средние расходы одного туриста (общие доходы от туризма, поделенные на количество туристов),

- количество фильмов, показанных на крупных кинофестивалях,

- количество иностранных корреспондентов в стране,

- количество объектов всемирного наследия ЮНЕСКО,

- ежегодная посещаемость топ-100 музеев,

${ }^{2}$ Soft Power 30. 2019. URL: https://softpower30.com (accessed 03.12.2019). 
- масштабы музыкального рынка,

- количество копий топ-10 альбомов, продаваемых за рубежом,

- олимпийские медали (лето/зима),

- рейтинг ФИФА (мужской),

- качество услуг национального авиаперевозчика,

- количество ресторанов со звездами Мишлен,

- индекс влиятельности языка (Power Language Index).

2) Цифровая сфера:

- подписчики аккаунта главы государства в Facebook (за пределами страны),

- коэффициент вовлеченности по аккаунтам главы государства / правительства в Facebook (за пределами страны),

- подписчики в Facebook аккаунтов министерства иностранных дел (за пределами страны),

- коэффициент вовлеченности по аккаунтам министерства иностранных дел в Facebook (за пределами страны),

- количество интернет-пользователей (на 100 жителей),

- защищенные интернет-серверы (на млн жителей),

- мобильные телефоны (на 100 чел.),

- пропускная способность интернета (в тыс. Мбит/с),

- индекс государственных электронных услуг (government online services index),

- индекс электронного участия (e-participation index),

- количество абонентов широкополосной связи (на 100 жителей).

3) Образование:

- средний балл по естественным наукам, математике и чтению (OECD PISA),

- общий показатель зачисления в высшие учебные заведения,

- количество ведущих глобальных университетов,

- количество опубликованных статей в академических научных журналах,

- количество иностранных студентов,

- расходы на образование (в \% от ВВП).

4) Вовлеченность:

- общая помощь развитию зарубежным странам,

- количество посольств за рубежом,

- количество посольств в стране,

- количество генеральных консульств за рубежом,

- количество постоянных представительств при многосторонних организациях,

- членство в международных организациях,

- количество подписанных экологических договоров,

- число просителей убежища на 1000 человек,

- количество дипломатических культурных миссий,

- количество стран, которые гражданин может посещать без визы,

- недельная аудитория государственной вещательной компании,

- индекс экологической эффективности (Environmental Performance Index).

5) Предпринимательство:

- количество глобальных патентных заявок (в \% к ВВП),

- индекс конкурентоспособности всемирного экономического форума (WEF Competitiveness Index), 
- прямые иностранные инвестиции (в \% от ВВП),

- индекс экономической свободы heritage (heritage economic freedom index),

- индекс восприятия коррупции (corruption perceptions index),

- расходы на НИОКР (в \% от ВВП),

- глобальный инновационный индекс (global innovation index),

- количество сотрудников МСП (в \% от рабочей силы),

- индекс легкости ведения бизнеса всемирного банка (World Bank Ease Of Doing Business Report),

- уровень безработицы (в \% от рабочей силы),

- доля высокотехнологичного экспорта (в \% от экспорта промышленной продукции),

- затраты на открытие стартапа (World Banklog, в \% от валового национального дохода на душу населения).

6) Управление:

- индекс человеческого развития (Human Development Index),

- индекс Freedom House,

- количество исследовательских центров,

- индекс гендерного равенства (Gender Equality Index),

- индекс демократии the economist (Economist Democracy Index),

- размеры теневой экономики (в \% от ВВП),

- количество убийств (на душу населения),

- показатель всемирного банка по голосованию и подотчетности (World

Bank Voice And Accountability Index),

- число приведенных в исполнение смертных приговоров,

- уровень неравенства доходов (индекс Джини),

- индекс доверия правительству всемирного экономического форума (World Economic Forum Trust In Government Index),

- индекс свободы прессы (Press Freedom Index),

- индекс эффективности правительства всемирного банка (World Bank Government Effectiveness),

- индекс качества государственного регулирования всемирного банка (World Bank Good Governance Regulation Quality),

- индекс верховенства закона всемирного банка (World Bank Good Governance Rule Of Law).

\section{МЕТОДОЛОГИЧЕСКИЕ ПРОБЛЕМЫ ИЗМЕРЕНИЯ МЯГКОЙ СИЛЫ: РЕЦЕПТЫ ОПЕРАЦИОНАЛИЗАЦИИ}

Основные индикаторы мягкой силы описывают “скрытые ресурсы” власти ${ }^{3}$. Это ресурсы, или активы, которые пассивно (наподобие религиозных центров) оказывают влияние как на людей, так и на лидеров других наций. Эти индикаторы близки к переменным, которые мы находим в литературе по мягкой силе (см. табл. 3) [Chatin, Gallarotti 2016].

Эти индикаторы в целом исчерпывающе характеризуют государство как крайне влиятельное в мировом сообществе, уважаемое за множество черт,

\footnotetext{
${ }^{3}$ Используемая здесь типология (скрытая, явная и эффективная мягкая сила) адаптирована по методологии исследования [Trunkos, Cerny 2018].
} 
которые делают его желательным местом для жизни, посещения или подражания. Такое государство - магнит для представителей других государств и народов, образец для подражания для лидеров и граждан других наций, объект уважения и даже обожания со стороны остального мира.

Очевидный методологический вопрос возникает в контексте противопоставления жесткой и мягкой силы. В некоторых случаях существуют значительные пересечения с жесткой силой. Зарубежная помощь содержит значительную "жесткую составляющую”, так как в ней присутствует элемент генерирования влияния посредством экономической мощи, которая относится к жесткой силе. В зарубежной помощи присутствует компонент доброй воли, однако его крайне трудно отделить от связанной с экономической составляющей жесткой “покупательской способности”.

Индикаторы экономического, технологического, правительственного и международного присутствия также могут отражать потенциал жесткой силы, так как оценивают потенциал материальных ресурсов, которые могут быть использованы для усиления влияния нации на мировой арене. Исследования активизации мягкой силы рядом государств, такие как работа Джошуа Курлянчика "Харизматичное наступление" [Kurlantzick 2007], недостаточно раскрывают проблему сосуществования жесткой и мягкой силы. И Китай, и Южная Корея действительно реализуют проекты, которые можно считать инициативами по развитию мягкой силы, однако концептуальный базис экономических стратегий этих стран таков, что нацеливает их прежде всего на обеспечение доступа к ресурсам и инвестициям (форвардные контракты, связанная помощь).

таблица 3 (Table 3)

\section{Истоиники мягкой силы}

Sources of Soft Power

\begin{tabular}{|c|c|}
\hline $\begin{array}{l}\text { Международные } \\
\text { источники }\end{array}$ & $\begin{array}{l}\text { - Уважение к международным законам, нормам и институтам. } \\
\text { - Фундаментальная опора на многосторонность, воздержанность } \\
\text { от чрезмерной односторонности. } \\
\text { - Соблюдение международных договоров и обязательств. } \\
\text { - Готовность пожертвовать краткосрочными национальными } \\
\text { интересами для общего блага. } \\
\text { - Либеральная внешнеэкономическая политика. }\end{array}$ \\
\hline $\begin{array}{l}\text { Национальные } \\
\text { источники }\end{array}$ & $\begin{array}{l}\text { Культура } \\
\text { - Выраженная социальная сплоченность. } \\
\text { - Повышенное качество жизни. } \\
\text { - Свобода. } \\
\text { - Достаточные возможности. } \\
\text { - Толерантность. } \\
\text { - Притягательность образа жизни. } \\
\text { - Культурное первенство и влияние. } \\
\text { Политические институть } \\
\text { - Демократия. } \\
\text { - Конституционность. } \\
\text { - Либерализм/плюрализм. } \\
\text { - Профессиональная бюрократия. }\end{array}$ \\
\hline
\end{tabular}

Значительная проблема применяемой методологии состоит в том, что целый ряд индикаторов в различных подындексах недостаточно полно отражает соответствующие показатели. Например, индикатор трансграничных миграционных потоков, призванный характеризовать привлекательность страны, не учитывает нелегальных мигрантов, а также потенциальных мигрантов тех, кто хотел бы переехать в страну, но по различным причинам не имеет такой возможности. Более корректный индикатор должен отражать данные по 
этим двум категориям мигрантов. Безусловно, такие данные найти непросто, ведь подходящих источников мало (за исключением данных опросов самих стран, составленных по их собственной методологии).

Аналогичной критики заслуживает индикатор статистики посещаемости, применяемый для оценки туристической привлекательности страны. Существует множество причин, по которым люди не могут посетить ту или иную страну (наличие трудностей с получением визы, препятствий для выезда, финансовые ограничения). Опросы массового мнения могли бы помочь выявить более надежные показатели оценки туристической привлекательности.

Недостаточно оценивают потенциал ряда факторов и такие индикаторы, как иностранные инвестиции, вовлеченность в социальные сети и обучение за рубежом. Наиболее надежным свидетельством желательности контакта следует считать не то, какой объем средств удалось привлечь в страну, сколько в ней обучается студентов или сколько насчитывается подключений к Facebook. Koppeктнее было бы оценивать более масштабный потенциал контакта, который возник бы при отсутствии ограничений на эту деятельность (например, интернет-блокировки, ограничительные квоты для студентов, инвестиционные барьеры). Именно в этом случае большинство индикаторов фактической активности недостаточно полно свидетельствуют о привлекательности той или иной страны, поскольку потенциальная активность (в мире, где не было бы ограничений) намного выше, чем учитываемая замерами наличная активность. Истинная привлекательность проявляется в том, хотят ли субъекты на самом деле предпринимать такие действия, а не в том, способны ли они это сделать в реальности. Измерить желание, а не потоки сложно, но эту проблему можно решить. Замеры в некоторых странах, которые блокируют спрос на глобальные связи, пришлось бы проводить в условиях, вовсе не способствующих научным оценкам мнения населения (Китай, Северная Корея). Но такие опросы можно было бы и провести надежно с точки зрения научной достоверности на базе исследования в среде проживающих за рубежом соотечественников. Это было бы верно для каждой переменной, которая систематически не учитывает потенциальные контакты.

Что же касается политической сферы, то шкала количественных показателей смещена в сторону либерально-демократических ценностей. В то время как индикаторы, позволяющие оценить мягкую силу автократий, уже существуют, по-прежнему отсутствуют индикаторы, которые бы дали возможность оценить лидерские качества и способность правительств реагировать на кризисы. Недостаток индикаторов для оценки мягкой силы автократий приводит к тому, что картина изучения этой категории за пределами группы либерально-демократических стран остается неполной. Не вызывает сомнений, что в рамках более комплексного анализа низкие показатели России и Китая по либерально-демократическим индикаторам будут скомпенсированы тем уважением, которым заручились лидеры этих стран, выводя их из кризисов и бедности.

Более надежные замеры позволят выявить показатели, которые отражают мягкое влияние различных политических режимов. Существует множество данных опросов, содержащих оценки автократий и их лидеров по таким показателям, как политическое управление в различных вопросах (экономическая стабильность, качество деловой среды, борьба с преступностью, создание имиджа и т.д.). Эти замеры показали бы ту степень уважения, которым эти режимы пользуются в сообществе наций, население которых может быть изучено с точки зрения научных критериев. 
Текущий подход к использованию индикаторов в области спорта также занижает престиж государств в этой сфере. Из-за акцента на позиции стран в футболе и Олимпийских играх упускаются из вида достижения национальных атлетов в других дисциплинах. Между тем, многие страны преуспели в таких видах спорта, как бейсбол, плавание, баскетбол, теннис, лыжи и многих других. Страна заслуживает гораздо большего уважения, если ее национальная команда добилась мирового лидерства в одной из ведущих спортивных дисциплин, нежели чем если она показала средние результаты на Олимпийских играх или Чемпионате мира по футболу. Эти индикаторы легко поддаются оценке - как по совокупности дисциплин, так и в рамках одной из них. Количественные оценки можно взвесить с точки зрения глобальной популярности конкретного вида спорта.

Пожалуй, главная проблема при измерении мягкой силы заключается в стандартизации и определении веса отдельных индикаторов. Без предварительного анализа данных невозможно четко определить относительную значимость показателей. Что сильнее - культурное влияние или достижения в области цифровых технологий? Превалирует ли религиозное влияние над этническим признанием? Как авторитет Саудовской Аравии как центра мусульманского мира соотносится с влиянием, которым она пользуется как центр арабского мира? Индекс Soft Power 30 определяет регрессии по зависимой переменной, построенные на основе опросов о предпочтительности той или иной страны. Это позволяет получить данные об относительной значимости переменных, и как следствие, выстроить ранжирование среди подындексов мягкой силы по степени влияния.

Некоторые переменные содержат характеристики как усиления, так и ослабления мягкой силы. К примеру, оценки президента России Владимира Путина по либерально-демократическим индикаторам оказываются низкими, однако он получает весьма высокие оценки по индикаторам, которые оценивают лидерские качества, такие как способность стабилизировать страну в условиях кризиса. Интегральный (“чистый”) показатель политического лидерства стал бы важным фактором оценки динамики власти и более надежным показателем оценки лидерства в целом.

Подобная интегральная оценка является единственным способом получения показателей чистой мягкой силы - индикаторов, которые учитывают все типы взаимодействия между значимыми переменными. Задача исследователя состоит в дисконтировании показателя "влияние" на базе характеристик, которые уменьшают мягкую силу. Во многих случаях переменные индекса Soft Power 30 учитывают эти интегральные, “чистые” эффекты (например, Индекс эффективности управления Всемирного банка учитывает некоторые из эффектов лидерства Путина), но эти индикаторы упускают из виду целый ряд аспектов. Например, ни один индикатор в подындексе управления не учитывает влияние на мягкую силу России таких факторов, как дискурс "хакерских атак на выборы в США” или “крымский кейс". Кроме того, нет ни одного показателя, который бы релевантно отражал восприятие американской мягкой силы, например, под влиянием президентства Трампа. Недостатки в "чистой" оценке указывают на более общее ограничение количественных показателей мягкой силы: они не обладают достаточной динамичностью. Многие из подындексов измеряют свойства, которые мало меняются из года в год (например, государственные институты и культурные объекты). Факторы текущей новостной динамики, такие как стрельба в школах, импульсивные поступки лидеров, внешнеполитические шоки учитываются недостаточно, что является предметом дальнейших корректирующих методологию усилий. 
Другая методологическая проблема измерений связана с объектами воздействия и с вопросом классификации. Количественные оценки могут быть дезагрегированы и организованы в зависимости от акторов, на которых направлено влияние носителей мягкой силы. Например, культурные факторы могут оказывать сильное прямое влияние на восприятие большей части населения или гражданского общества, но воздействовать на политических лидеров лишь косвенно. Замеры управленческих факторов будут иметь противоположный эффект в том смысле, что они будут оказывать более прямое влияние на лидеров и несколько менее прямое влияние на гражданское общество. Культурные объекты ЮНЕСКО сыграют выдающуюся роль в жизни национального гражданского общества (т.е. будут поощрять туризм в эту страну), но в несколько меньшей степени окажут влияние на повседневные функции национальных лидеров и лиц, принимающих решения. Дипломатическая деятельность обусловливает повседневную жизнь национальных лидеров, но имеет гораздо менее прямое отношение к гражданскому обществу. С точки зрения восприятия все факторы мягкой силы оказывают влияние на человеческую психологию независимо от целей, но с точки зрения прямого и косвенного воздействия, количественные показатели характеризуют факторы, которые по-разному влияют на разных участников. Это предполагает возможные различия в классификации в зависимости от цели воздействия. Можно различать факторы мягкой силы в зависимости от того, влияют ли они на восприятие (человеческая психология) или оказывают прямое влияние на повседневные функции акторов.

Аналогичным образом следует различать факторы, оказывающие наибольшее влияние, с одной стороны, на гражданское общество, и с другой стороны на национальных лидеров. Также можно разбить их по категориям. Например, можно наблюдать, насколько те или иные национальные лидеры и чиновники подвержены влиянию мягкой силы. Дипломатические ресурсы будут напрямую влиять на представителей государственных институтов зарубежных стран, тогда как эффективность управления может повлиять на решения высокого уровня с участием глав государств по вопросам формирования международных альянсов. Кроме того, круг целей воздействия мягкой силы может быть расширен, чтобы включить целый ряд других групп, на каждую из которых оказывают наибольшее влияние вполне конкретные факторы. Например, педагоги и ученые, очевидно, более подвержены влиянию факторов из категории “образование”. Для представителей деловых кругов более значимы факторы по направлениям “экономика" и “политическая коррупция", тогда как для гражданских активистов - то, как страна оценивается по уровню защиты государством прав человека и его политических свобод. Для популярных исполнителей, звезд шоу-бизнеса, очевидно, имеет наибольшее значение имидж страны с точки зрения индустрии развлечений и т.Д. - список таких корреляций весьма обширен.

Наконец, показатели в ведущих индексах мягкой силы представляют собой комбинацию трех ее ключевых проявлений. При проведении количественных исследований влияния мягкой силы ${ }^{4}$ (которые основаны главным образом на логических выводах из статистики, связанных с причинно-следственными связями), их надо обязательно разделять. В целом это замеры пассивной мягкой силы, которые могут функционировать как независимые переменные в количественных исследованиях (религиозные центры, ориентиры, индексы коррупции, индексы свободы, индексы прав человека, показатели экологической эффектив-

\footnotetext{
4 Здесь мы исходим из трехчастной классификации, предложенной Дж. Транкосом и Ф. Черни [Trunkos, Cerny 2018].
} 
ности). Они представляют собой характеристики, которые высоко оцениваются другими нациями, но обычно не включаются лидерами нации в арсенал средств мягкой силы, применяемых для того, чтобы оказывать влияние.

Существует другой подход к определению независимых переменных в количественных исследованиях влияния мягкой силы. Это, очевидно, активные меры, принимаемые правительствами для усиления ${ }^{5}$ своего мягкого влияния. Например, количество миссий, которые страны размещают в иностранных государствах, или количество подписанных международных договоров. Третий тип показателей, которые преобладают в этих индексах, - это индикаторы, которые в большей степени отражают фактическое влияние факторов мягкой силы на другие страны. Говоря конкретнее, они представляют собой показатели актуализации или влияния мягкой силы. Такие переменные, очевидно, хорошо выступают в роли зависимых переменных в количественных исследованиях мягкой силы. Например, численность беженцев, или иммигрантов, или кинозрителей.

Мы перестроили показатели мягкой силы из индекса Soft Power 30 (см. ниже), разбив их по этим трем функциональным типам. Такая классификация позволяет осуществлять более точный количественный анализ причин и следствий мягкой силы в международных отношениях. Наш анализ базируется прежде всего на статистических данных о причинно-следственных связях, связанных с мягкой силой, при этом независимые переменные делятся на пассивные и активные, и проводится различие между источниками мягкой силы как зависимыми и независимыми переменными. Представляется, что такой подход будет полезен исследователям, в задачи которых выходит изучение причинно-следственных связей, связанных с ресурсами мягкой силы.

\section{ПРЕДЛАГАЕМАЯ КЛАССИФИКАЦИЯ ПОКАЗАТЕЛЕЙ МЯГКОЙ СИЛЫ}

\section{Независимые переменные: пассивная мягкая сила'}

1) Культура:

- количество объектов всемирного наследия ЮНЕСКО,

- количество олимпийских медалей (лето/зима),

- рейтинг ФИФА (мужской),

- качество национального авиаперевозчика,

- количество ресторанов со звездами Мишлен,

- индекс влиятельности языка (Power Language Index).

2) Цифровая сфера:

- количество защищенных интернет-серверов (на 1 млн чел.),

- пропускная способность интернета (в тыс. Мбит/с),

- индекс государственных онлайн-услуг.

3) Образование:

- средний балл по естественным наукам, математике и чтению (OECD PISA),

- валовой показатель зачисления в высшие учебные заведения,

\footnotetext{
${ }^{5}$ Транкос и Черни называют первый тип латентным, а второй - открытым фактором мягкой силы. Между этими двумя факторами есть “серые зоны”. Например, правительства могут инвестировать в природоохранную политику или политику по борьбе с коррупцией, чтобы упрочить свои позиции на мировой арене, но сочетание факторов может быть не предназначено для этой цели.

${ }^{6}$ Некоторые из перечисленных показателей присутствуют в нескольких категориях из-за свойств “серой зоны”.
} 
- количество ведущих мировых университетов,

- количество статей в научных журналах,

- расходы на образование (в \% от ВВП).

4) Вовлеченность:

- индекс экологической эффективности (Environmental Performance Index).

5) Предпринимательство:

- количество глобальных патентных заявок (в \% к ВВП),

- индекс конкурентоспособности Всемирного экономического форума ( WEF Competitiveness Index),

- индекс экономической свободы Heritage (Heritage Economic Freedom Index),

- индекс восприятия коррупции (Corruption Perceptions Index),

- расходы на НИОКР (в \% от ВВП),

- глобальный инновационный индекс (Global Innovation Index),

- количество сотрудников МСП (в \% от рабочей силы),

- индекс легкости ведения бизнеса Всемирного банка (World Bank Ease of Doing Business Report),

- уровень безработицы (в \% от рабочей силы),

- доля высокотехнологичного экспорта (в \% от экспорта промышленной продукции),

- затраты на открытие стартапа (World BankLog, в \% от валового национального дохода на душу населения).

6) Государственное управление:

- индекс человеческого развития (Human Development Index),

- индекс Freedom House,

- количество исследовательских центров,

- индекс гендерного равенства (Gender Equality Index),

- индекс демократии (Economist Democracy Index),

- масштаб теневой экономики (в \% от ВВП),

- количество убийств (на душу населения),

- индекс учета мнения населения и подотчетности государственных органов Всемирного банка (World Bank Voice and Accountability Index),

- число смертных приговоров, приведенных в исполнение,

- неравенство доходов (коэффициент Джини),

- индекс доверия правительству Всемирного экономического форума (World Economic Forum Trust in Government Index),

- индекс свободы прессы (Press Freedom Index),

- индекс эффективности правительства Всемирного банка (World Bank Government Effectiveness),

- индекс качества государственного регулирования Всемирного банка (World Bank Good Governance Regulation Quality),

- индекс верховенства закона Всемирного банка (World Bank Good Governance Rule of Law).

\section{Независимые переменные: активная мягкая сила}

1) Культура:

- количество олимпийских медалей (лето/зима),

- качество национального авиаперевозчика. 
2) Цифровая сфера:

- количество интернет-пользователей (на 100 жителей),

- количество защищенных интернет-серверов (на 1 млн чел.),

- пропускная способность интернета (тыс. Мбит/с),

- индекс государственных онлайн-услуг (Government Online Services Index),

- количество абонентов широкополосной связи (на 100 жителей).

3) Образование:

- средний балл по естественным наукам, математике и чтению (OECD PISA),

- валовой показатель зачисления в высшие учебные заведения,

- количество ведущих мировых университетов,

- количество статей, опубликованных в научных журналах,

- расходы на образование (в \% от ВВП).

4) Вовлеченность:

- общая помощь развитию зарубежным странам,

- количество посольств за границей,

- количество посольств в стране,

- количество генеральных консульств за рубежом,

- количество постоянных представительств при многосторонних организациях,

- членство в международных организациях,

- количество ратифицированных договоров в сфере экологии,

- количество дипломатических культурных миссий,

- количество стран, которые гражданин может посещать без визы,

- индекс результативности экологической деятельности (Environmental Performance Index).

5) Предпринимательство:

- количество поданных глобальных патентов (в \% от ВВП),

- расходы на НИОКР (в \% от ВВП),

- глобальный индекс инноваций (Global Innovation Index),

- индекс легкости ведения бизнеса всемирного банка (World Bank Ease of Doing Business Report),

- уровень безработицы (в \% от рабочей силы),

-доля высокотехнологичного экспорта (в \% от экспорта промышленной продукции).

6) Управление:

- индекс человеческого развития (Human Development Index),

- индекс Freedom House,

- количество исследовательских центров,

- индекс гендерного равенства (Gender Equality Index),

- индекс демократии (Economist Democracy Index),

- количество убийств (на душу населения),

- индекс учета мнения населения и подотчетности государственных органов Всемирного банка (World Bank Voice and Accountability Index),

- число смертных приговоров, приведенных в исполнение,

- индекс доверия правительству Всемирного экономического форума (World Economic Forum Trust in Government Index), 
- индекс свободы прессы (Press Freedom Index),

- индекс эффективности правительства Всемирного банка (World Bank Government Effectiveness),

- индекс качества государственного регулирования Всемирного банка (World Bank Good Governance Regulation Quality),

- индекс верховенства закона Всемирного банка (World Bank Good Governance Rule of Law).

\section{Зависимые переменные: влияние мягкой силы}

1) Культура:

- общее количество прибывающих туристов,

- средние расходы туриста (общие доходы от туризма, поделенные на количество туристов),

- количество фильмов, показанных на крупных кинофестивалях,

- количество иностранных корреспондентов в стране,

- ежегодная посещаемость топ-100 музеев,

- масштабы музыкального рынка,

- количество копий топ-10 альбомов, проданных за рубежом,

- индекс влиятельности языка (Power Language Index).

2) Цифровая сфера:

- подписчики аккаунтов глав государств в Facebook (за пределами страны),

- коэффициент вовлеченности по аккаунтам глав государств и правительств в Facebook (за пределами страны),

- подписчики аккаунтов министерств иностранных дел в Facebook (за пределами страны),

- коэффициент вовлеченности по аккаунтам министерств иностранных дел в Facebook (за пределами страны),

- количество интернет-пользователей (на 100 жителей),

- защищенные интернет-серверы (на млн жителей),

- мобильные телефоны (на 100 чел.),

- пропускная способность интернета (в тыс. Мбит/с),

-правительственный индекс онлайн-услуг (Government Online Services Index),

- индекс электронного участия (E-Participation Index),

- количество абонентов широкополосной связи (на 100 жителей).

3) Образование:

- количество иностранных студентов в стране.

4) Взаимодействие:

- число просителей убежища на 1000 чел.,

- размер недельной аудитории государственного вещателя.

5) Предпринимательство:

- прямые иностранные инвестиции (в \% от ВВП).

Как можно видеть, имеет место ряд пересечений между двумя категориями зависимых переменных, однако крайне мало пересечений между категориями зависимых и независимых переменных в целом. Это наблюдение значительно упрощает количественный анализ влияния мягкой силы. 


\title{
ВЫВОДЫ
}

Концепт мягкой силы - один из важнейших инструментов анализа международных отношений. Этот инструмент продолжает развиваться, в том числе в части методов оценки мягкой силы, которые все еще далеки от совершенства. Настоящая статья содержит предложения по возможным индикаторам такой оценки, которые могут служить предметом для обсуждения и дальнейшей доработки методологии анализа мягкой силы.

(Перевод с англ. С. Чугрова)

DOI: $10.17976 / j p p s / 2020.01 .07$

\section{HOW TO MEASURE SOFT POWER IN INTERNATIONAL RELATIONS}

\author{
G.M. Gallarotti ${ }^{1}$ \\ ${ }^{1}$ Wesleyan University. Middletown, USA
}

GALLAROTTI, Giulio M., Professor, Department of Government, Wesleyan University, Middletown, email: ggallarotti@wesleyan.edu

Gallarotti G.M. How to Measure Soft Power in International Relations. - Polis. Political Studies. 2020. No. 1. P. 89-103. (In Russ.) https://doi.org/10.17976/jpps/2020.01.07

\begin{abstract}
Acknowledgements. For comments on the draft, the author would like to thank Sergey Chugrov, Alina Vladimirova and participants of the panel "Power Audit in International Relations" at the meeting of the International Political Science Association, Brisbane Australia, July 21-24, 2018. The author is grateful to Wesleyan University for financial support in attending the conference.
\end{abstract}

Received: 01.01.2019. Accepted: 11.11.2019

\begin{abstract}
This paper provides suggestions on how to properly operationalize "soft power" in international relations and organize the measures into categories that are more favorable for quantitative analyses. While we mention several existing indexes, analysis concentrates on the best known and most extensively applied index of "soft power": The "Soft Power" 30 Index. So far, the actually measures used for quantitative analysis based on these most popular data sets have been flawed. This paper attempts to illuminate these flaws and prescribes solutions for improving the measures. In this respect, the paper serves as an important prelude to quantitative studies of soft power. This paper is organized as follows: first, the author presents the leading measures of soft power by data base and content of each. Then he identifies flaws in measuring "soft power" and prescribes better measures. The last section offers brief concluding remarks.
\end{abstract}

Keywords: soft power, hard power, quantitative research methods, indices, operationalization, international relations.

\section{References}

Chatin M., Gallarotti G. 2016. The BRICS and Soft Power: An Introduction. - Journal of Political Power. Vol. 9. No. 3. P. 335-352. https://doi.org/10.1080/2158379x.2016.1232284

Elenco Global Presence Report 2015. Coordinators: L. Olivié. C. García-Calvo, M Gracia. 2015. Madrid: Real Instituto Elcano. URL: http://www.realinstitutoelcano.org/wps/wcm/connect/f36b5f004830c24a8e3 b8fe0dd72d861/Global_Presence_2015.pdf?MOD=AJPERES\&CACHEID=f36b5f004830c24a8e3b8fe0d d72d861 (accessed 16.12.2019).

Kurlantzick J. 2007. Charm Offensive: How China's Soft Power is Transforming the World. New Haven: Yale University Press.

McClory J. 2012. The New Persuaders III. A 2012 Global Ranking of Soft Power. London: Institute for Government. 15 p. URL: https://www.instituteforgovernment.org.uk/sites/default/files/publications/The\%20 new\%20persuaders\%20III_0.pdf (accessed 16.12.2019).

Trunkos J., Cerny Ph. 2018. Operationalization Soft Power from Latent to Manifest. Paper delivered at the annual meeting of the International Political Science Association, Brisbane, Australia, July 20-24. 